This article was downloaded by: [National Taiwan University]

On: 8 April 2009

Access details: Access Details: [subscription number 731836271]

Publisher Informa Healthcare

Informa Ltd Registered in England and Wales Registered Number: 1072954 Registered office: Mortimer House, 37-41 Mortimer Street, London W1T 3JH, UK

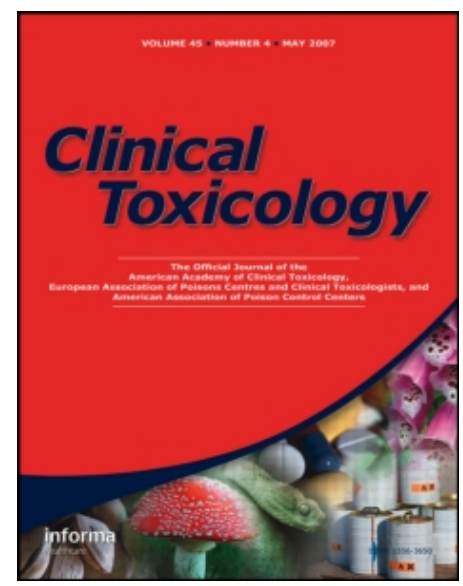

\title{
Clinical Toxicology
}

Publication details, including instructions for authors and subscription information:

http://www.informaworld.com/smpp/title content=t713597279

\section{Dimethylacetamide, Ethylenediamine, and Diphenylmethane Diisocyanate Poisoning Manifest as Acute Psychosis and Pulmonary Edema: Treatment with Hemoperfusion}

Ta-Chen Su a; Pei-Hong Lin a; Ming-Jang Chiu a; Tzong-Shinn Chu a; Ming J. W. Chang b; Jung-Der Wang a; Tsun-Jen Cheng ac

a National Taiwan University Hospital, Taipei, Taiwan ${ }^{\mathrm{b}}$ College of Medicine, Chang Gung University, Taipei,

Taiwan ${ }^{c}$ Institute of Occuptional Medicine and Industrial Hygiene, College of Public Health, National Taiwan

University, Taipei, Taiwan

Online Publication Date: 24 July 2000

To cite this Article Su, Ta-Chen, Lin, Pei-Hong, Chiu, Ming-Jang, Chu, Tzong-Shinn, Chang, Ming J. W., Wang, Jung-Der and Cheng, Tsun-Jen(2000)'Dimethylacetamide, Ethylenediamine, and Diphenylmethane Diisocyanate Poisoning Manifest as Acute Psychosis and Pulmonary Edema: Treatment with Hemoperfusion',Clinical Toxicology,38:4,429 — 433

To link to this Article: DOI: $10.1081 / C L T-100100953$

URL: http://dx.doi.org/10.1081/CLT-100100953

\section{PLEASE SCROLL DOWN FOR ARTICLE}

Full terms and conditions of use: http://www.informaworld.com/terms-and-conditions-of-access.pdf

This article may be used for research, teaching and private study purposes. Any substantial or systematic reproduction, re-distribution, re-selling, loan or sub-licensing, systematic supply or distribution in any form to anyone is expressly forbidden.

The publisher does not give any warranty express or implied or make any representation that the contents will be complete or accurate or up to date. The accuracy of any instructions, formulae and drug doses should be independently verified with primary sources. The publisher shall not be liable for any loss, actions, claims, proceedings, demand or costs or damages whatsoever or howsoever caused arising directly or indirectly in connection with or arising out of the use of this material. 


\title{
Dimethylacetamide, Ethylenediamine, and Diphenylmethane Diisocyanate Poisoning Manifest as Acute Psychosis and Pulmonary Edema: Treatment with Hemoperfusion
}

Ta-Chen Su; Pei-Hong Lin; Ming-Jang Chiu; Tzong-Shinn Chu; Ming J. W. Chang; Jung-Der Wang; Tsun-Jen Cheng

National Taiwan University Hospital, Taipei, Taiwan (T-CS, P-HL, M-JC, T-SC, $J$-DW, T-JC); College of Public Health, National Taiwan University, Taipei, Taiwan (T-CS, J-DW, T-JC); College of Medicine, Chang Gung University, Taipei, Taiwan (MJWC)

\begin{abstract}
Case Report: A 27-year-old man, employed by a synthetic fiber company, had been exposed to dimethylacetamide, ethylenediamine, and diphenylmethane diisocyanate in a confined space continuously for 4-6 hours per day for 3 days before admission. Hallucinations and delusions were noted at admission; pulmonary edema developed subsequently. The electroencephalogram showed diffuse moderate cortical dysfunction and slow waves at 4-7 Hz, 20-80 $\mu \mathrm{V}$. Seizures, liver injury, and rhabdomyolysis were noted on the 4th hospital day. The patient was treated by hemoperfusion with a decrease in urine dimethylacetamide from $3265 \mathrm{mg} / \mathrm{g}$ to $4 \mathrm{mg} / \mathrm{g}$ creatinine over 4 days. Serial urinary dimethylacetamide and electroencephalogram correlated with the clinical condition.
\end{abstract}




\section{INTRODUCTION}

Dimethylacetamide (DMAC) (CAS No. 127-19-5), an excellent dipolar and versatile industrial solvent with wide organic and inorganic solubility and water miscibility has been widely applied in the manufacturing industry. ${ }^{1}$ DMAC is well absorbed by the dermal and inhalational routes. ${ }^{2}$ Animal studies have shown liver damage in acute DMAC intoxication; ${ }^{3}$ however, the human data on DMAC toxicity remain limited.

Urinary $N$-methylacetamide (MMAC), assayed by gas chromatography, is commonly used to monitor occupational exposure to DMAC. Biomonitoring is superior to airborne concentration monitoring in the detection of excessive DMAC exposure. ${ }^{4}$

We report a case of severe DMAC, ethylenediamine (EDA), and diphenylmethane diisocyanate (MDI) intoxication with a description of the serial changes in the electroencephalogram (EEG) and urinary MMAC measurements. The response to treatment by hemoperfusion is discussed.

\section{Case Report}

A previously healthy 27 -year-old man had been employed for 1 year by a chemical factory where synthetic elastic fiber was synthesized from polytetramethylene glycol (PTG) (CAS No. 25190-06-1) and diphenylmethane diisocyanate (MDI) (CAS No. 101-68-8). In the manufacturing process, EDA (CAS No. 107-15-3) was used as a catalyzer and DMAC as the solvent. After polymerization, DMAC was used to clean the reaction tank and collected into a recycling tank where the solid remains (2\%) were separated from DMAC $(98 \%)$. There was no further analysis of the $2 \%$ solid remains, which were described as elastic fiber polymer. It is presumed that small amounts of EDA, MDI, PTG, and their incomplete reaction products were also part of the solid remains. The recycling tank was an enclosed cylindrical container with limited ventilation. Since cleaning was not performed regularly, the reaction debris of solid compounds had accumulated and obstructed the container outlet. The employee had been assigned to clean up the debris in the

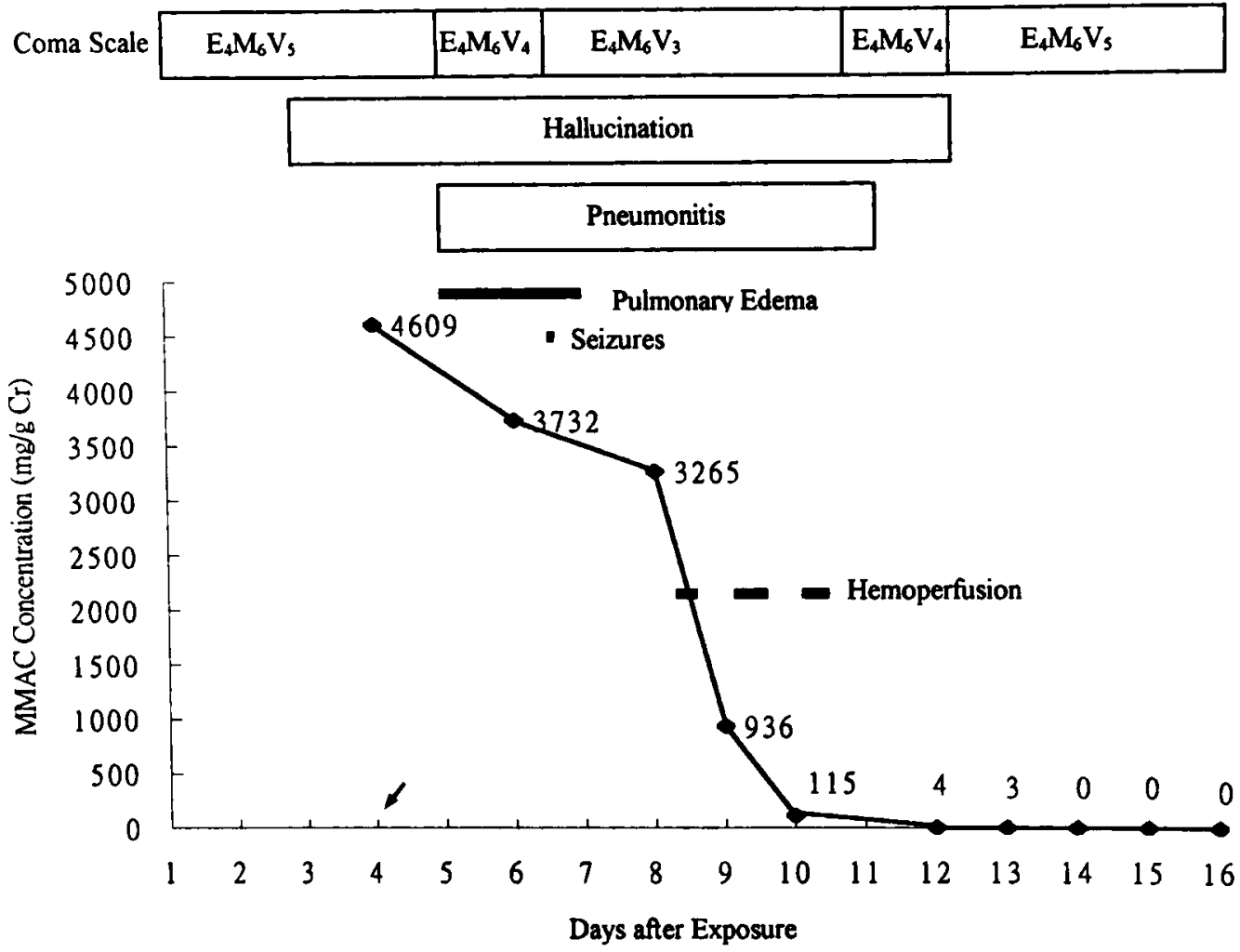

Figure 1. Urinary $N$-methylacetamide concentration after exposure to the DMAC mixture and clinical course before and after hemoperfusion treatment. Arrow $\measuredangle$ marks the 1st hospital day. 
closed tank without respiratory or skin protection for 3 consecutive working days, 4 to 6 hours each day. The patient reported that he had leaned against or sat in the solid debris while working because of the limited space in the cylinder.

Delusion and paranoia with visual hallucination developed in the early morning of day 4 (hospital day 1). At this time, ulceration of the entire buttocks was noted. Laboratory tests revealed leukocytosis, mildly elevated alanine aminotransferase (ALT) and aspartate aminotransferase (AST), and markedly increased creatinine phosphokinase (CPK) of 7049 IU/L.

On hospital day 2, the patient became drowsy and delirious with poor attention span, agitation, and incoherent speech. He had tachycardia with mild respiratory distress. The chest X-ray and pulmonary computed tomography (CT) scan showed bilateral diffuse interstitial infiltrate. The EEG revealed diffuse slow (theta) waves at 2.5-7 $\mathrm{Hz}, 20-80 \mu \mathrm{V}$ with generalized beta activities at $15-17$ $\mathrm{Hz}, 10-20 \mu \mathrm{V}$.

On hospital day 3 , he had recurrent generalized tonicclonic seizures followed by deterioration of consciousness. This was ascribed to pulmonary edema with hypoxemia ( $\mathrm{pH}$ 7.37, $\mathrm{PaCO}_{2} 34.4 \mathrm{mmHg}, \mathrm{PaO}_{2} 36.1 \mathrm{mmHg}$, $\mathrm{HCO}_{3}{ }^{-} 19.5 \mathrm{mEq} / \mathrm{L}$, and base-excess -4.5$)$. CT scan of the brain on hospital day 4 revealed diffuse mild brain swelling. Glycerol and steroids but no sedatives were given. Bronchoscopy on hospital day 4 showed hyperemic edema of the tracheobronchial tree, consistent with inhalational injury. Intubation was not performed. Upper gastrointestinal (UGI) bleeding and conjunctivitis were noted on the 5th to 9th hospital days. Panendoscopy for evaluation of UGI bleeding revealed oral mucositis, fungal esophagitis, and gastric erosion, which were treated with famotidine and fluconazole.

Since consciousness was not restored, a therapeutic trial of hemoperfusion with activated charcoal was performed for 5 hours per day $\times 3$ on the 6th through the 8th hospital days, employing hemoperfusion cartridges of Gambro Adsorba 300C (Gambro Dialysatoren GmbH \& Co KG, Hechingen, Germany) at a blood flow of $150 \mathrm{~mL} / \mathrm{min}$ with 300 units heparin/h. Subsequently, his condition improved and he was discharged on the 29th hospital day with good recovery.

\section{Measurement of Urinary $N$-methylacetamide}

Cold methanol $2 \mathrm{~mL}$ was added to $1 \mathrm{~mL}$ urine to denature the proteins, which were then removed by a brief centrifugation. The supernatant was analyzed with China
GC $8700 \mathrm{~F}$ on a DB-264 column using flame ionization detection. ${ }^{5}$ The patient's urine was collected for MMAC testing on the 4th, 6th, 8th-10th, and 12th-16th day after initial DMAC exposure.

The biological exposure index (BEI) of MMAC is 35 $\mathrm{mg} / \mathrm{g}$ creatinine $(\mathrm{Cr}){ }^{4}$ The urinary MMAC level on admission was $4609 \mathrm{mg} / \mathrm{g} \mathrm{Cr}$, decreasing to $3265 \mathrm{mg} / \mathrm{g} \mathrm{Cr}$ before hemoperfusion. After the 1st, 2nd, and 3rd course of hemoperfusion, the MMAC levels decreased to 936, 115 , and $4 \mathrm{mg} / \mathrm{g} \mathrm{Cr}$, respectively. The MMAC levels were no longer detectable on the 5th day after hemoperfusion (Figure 1).

\section{EEG Recordings and Findings}

All EEGs were recorded digitally with subsequent quantitative analysis. Nonsleep, artifact-free EEG segments were selected and then underwent spectrum analyses through fast Fourier transformation (FFT). Peak frequencies and summation amplitudes of different frequency bands were obtained. The frequency bands were conventionally defined, i.e., delta band $0.5-3 \mathrm{~Hz}$, theta band $4-7 \mathrm{~Hz}$, alpha band $8-13 \mathrm{~Hz}$, and beta band 14-24 Hz.

On day 5 , there were frequent intermittent diffuse theta waves at $4-7 \mathrm{~Hz}, 20-80 \mu \mathrm{V}$ and occasional intermittent diffuse delta waves at $2.5-3 \mathrm{~Hz}, 30-70 \mu \mathrm{V}$ with

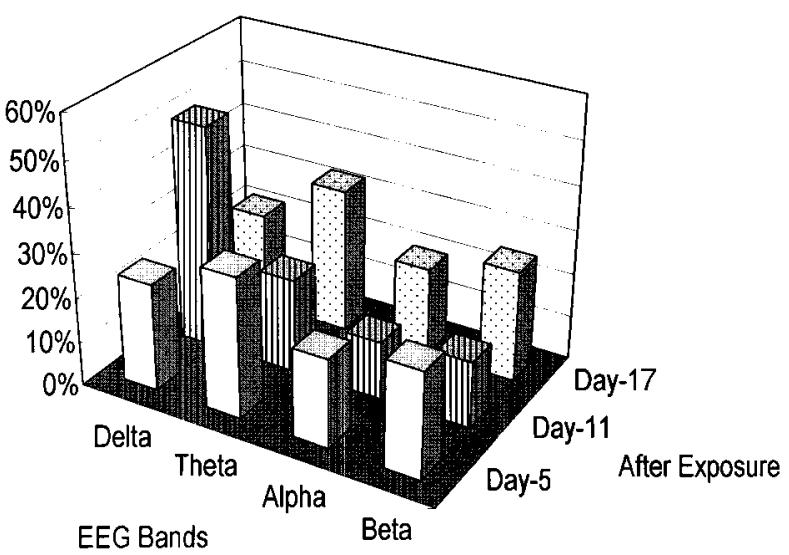

Figure 2. Distribution of the amplitude spectra in the different EEG recordings. The EEG on day 5 after the initial DMAC exposure, the band percentages were delta $24.3 \%$, theta $31.8 \%$, alpha $20.0 \%$, and beta $24.0 \%$. After clinical deterioration, the delta band increased to $50.4 \%$, and the fast activities decreased to alpha $13.2 \%$ and beta $15.0 \%$ by day 11 . By day 17 , the delta band shrank to $8 \%$ and fast activity increased to alpha $20.1 \%$ and beta $25.3 \%$. 
generalized beta activities at $15-17 \mathrm{~Hz}, 10-20 \mu \mathrm{V}$. The follow-up on day 11 showed deterioration of the cortical function with nearly continuous diffuse theta waves at 4-7 Hz, 20-50 $\mu \mathrm{V}$ intermixed with or intervened by occasional bursts of generalized sharp waves or delta waves at $1-3 \mathrm{~Hz}, 30-90 \mu \mathrm{V}$. The EEG on day 17 , after improvement of the consciousness, showed intermittent diffuse theta waves at 4-7 Hz, 20-50 $\mu \mathrm{V}$, occasional diffuse intermittent delta waves at $2-3 \mathrm{~Hz}, 30-60 \mu \mathrm{V}$ against a background of low cerebroelectric activities, and diffuse beta activities at $15-20 \mathrm{~Hz}, 5-10 \mu \mathrm{V}$ mostly in the frontocentral regions. Attenuation of alpha activities was observed in all three recordings.

Peak frequencies shifted from $5.0 \pm 0.9 \mathrm{~Hz}$ on day 5 to $1.2 \pm 0.4 \mathrm{~Hz}$ on day 11 and to $3.3 \pm 1.2 \mathrm{~Hz}$ on day 17. The distribution of the normalized amplitude spectrum for different frequency bands showed a similar evolution (Figure 2).

\section{DISCUSSION}

This patient manifested hallucinations, delusions, skin burns, hepatitis, inhalational injury and rhabdomyolysis, similar to those of a case of combined exposure of DMAC and EDA. ${ }^{6}$ However, the clinical course in this case was further complicated by pulmonary edema and disturbed consciousness 48 hours after the cessation of exposure.

EDA and MDI are both respiratory sensitizers and can induce dyspnea, wheezing, runny nose, and coughing. DMAC has been reported to be associated with bronchitis; however, pneumonitis with pulmonary edema has not been reported after pure DMAC exposure in humans. Pulmonary edema and bronchopneumonia have been observed in animals exposed to high concentrations of EDA. ${ }^{7}$ High aerosol concentrations of MDI could cause chemical pneumonitis and pulmonary edema, which can develop in several hours or be delayed up to 48 hours after exposure and are aggravated by physical exertion. ${ }^{8}$ Thus, EDA or MDI could be responsible for inhalational injury and pulmonary edema.

Abnormal mental states, including various levels of confusion, disorientation, or hallucination were found in all 15 patients with advanced malignancies treated with DMAC $400 \mathrm{mg} / \mathrm{kg}$ for 3 or more days. ${ }^{9,10}$ Elevation of serum transaminase was also seen in 7 of 15 patients in the same study. The elevation of liver enzymes in this patient was relatively mild.

Extracorporeal perfusion for the treatment of DMAC intoxication has not been reported. ${ }^{6}$ The patient presented with acute pulmonary edema due to chemical pneumonitis, had a progressive deterioration of consciousness, and the urinary MMAC level was over 100 times the BEI. We attempted to supplement the renal clearance of lipid soluble DMAC, EDA, and MDI by activated charcoal hemoperfusion. ${ }^{11}$ The urinary concentration of MMAC did decrease rapidly during hemoperfusion, and was nondetectable on day 5 after hemoperfusion. The slope of urinary MMAC level before hemoperfusion was -336 $\mathrm{mg} / \mathrm{g} \mathrm{Cr}$ per day or about one-fifth of that during hemoperfusion (slope $=-1575 \mathrm{mg} / \mathrm{g} \mathrm{Cr}$ per day), as shown in Figure 1.

A study by Kennedy et al. concluded that changes in DMAC exposures could be quantitatively reflected by urinary MMAC. ${ }^{12}$ Although there were no direct measurements of blood DMAC levels before and after hemoperfusion in this study, the urinary MMAC levels before and after hemoperfusion (24-hour interval) were only a biomonitoring index. This patient's pulmonary edema was resolved and his consciousness and general condition improved simultaneously after hemoperfusion. The relation of the possible removal of EDA and MDI, both potent respiratory sensitizers and irritants, to the pulmonary status improvement remains speculative.

The CNS toxicity in our patient included delirium, hallucinations, and impaired consciousness, consistent with previous reports of DMAC intoxication; it resembled the syndrome produced by lysergic acid diethylamide characterized by increased beta activities on EEG. $^{13}$

\section{REFERENCES}

1. Kennedy GL. Biologic effects of acetamide, formamide, and their monomethyl and dimethyl derivatives. CRC Crit Rev Toxicol 1986;17:129-182.

2. Maxfield ME, Barnes JR, Azar A, et al. Urinary excretion of metabolite following human exposure to dimethylformamide or dimethylacetamide. J Occup Med 1975;17: 506-511.

3. Kennedy GL, Sherman H. Acute and subchronic toxicity of dimethylformamide and dimethylacetamide following various routes of administrations. Drug Chem Toxicol 1986;9:147-170.

4. Spies GJ, Rhyne RH, Evans RA, et al. Monitoring acrylic fiber workers for liver toxicity and exposure to dimethylacetamide. J Occup Environ Med 1995;37:1093-1101.

5. Scailteur V, deHoffmann E, Buchet JP, Lauwerys R. Study on in vivo and in vitro metabolism of dimethylformamide in male and female rats. Toxicology 1984;29: $221-234$. 
6. Marino G, Anastopoulos H, and Woolf AD. Toxicity associated with severe inhalational and dermal exposure to dimethylacetamide and 1,2-ethanediamine. J Occup Med 1994;36:637-641.

7. Pozzani UC, Carpenter CP. Response of rats to repeated inhalation of ethylenediamine vapors. Arch Ind Hyg Occup Med 1954;9:223-226.

8. Karol MH. Respiratory effects of inhaled isocyanates. CRC Crit Rev Toxicol 1986;16:349-379.

9. Weiss AJ, Mancall EL, Koltes JA, White JC, Jackson LG. Dimethylacetamide: A hitherto unrecognized hallucinogenic agent. Science 1962;136:151-152.

10. Weiss AJ, Jackson LG, Carabasi RA, Mancall EL, White
JC. A phase I study of dimethylacetamide. Cancer Chem Rep 1962;16:477-485.

11. Goldfarb DS, Pond SM. Principles and techniques applied to enhance elimination of toxins. In: Goldfrank's Toxicologic Emergencies, 6th Ed. Goldfrank LR, Flomenbaum NE, Lewin NA, et al., eds., East Norwalk: Appleton \& Lange 1998:53-62.

12. Kennedy GL, Pruett JW. Biologic monitoring for dimethylacetamide: Measurement for 4 consecutive weeks in a workplace. J Occup Med 1989;31:47-50.

13. Brown BB. Subjective and EEG responses to LSD in visualizer and non-visualizer subjects. Electroencephalogr Clin Neurophysiol 1968;25:372-379. 


\section{Request Permission or Order Reprints Instantly!}

Interested in copying and sharing this article? In most cases, U.S. Copyright Law requires that you get permission from the article's rightsholder before using copyrighted content.

All information and materials found in this article, including but not limited to text, trademarks, patents, logos, graphics and images (the "Materials"), are the copyrighted works and other forms of intellectual property of Marcel Dekker, Inc., or its licensors. All rights not expressly granted are reserved.

Get permission to lawfully reproduce and distribute the Materials or order reprints quickly and painlessly. Simply click on the "Request

Permission/Reprints Here" link below and follow the instructions. Visit the U.S. Copyright Office for information on Fair Use limitations of U.S. copyright law. Please refer to The Association of American Publishers' (AAP) website for guidelines on Fair Use in the Classroom.

The Materials are for your personal use only and cannot be reformatted, reposted, resold or distributed by electronic means or otherwise without permission from Marcel Dekker, Inc. Marcel Dekker, Inc. grants you the limited right to display the Materials only on your personal computer or personal wireless device, and to copy and download single copies of such Materials provided that any copyright, trademark or other notice appearing on such Materials is also retained by, displayed, copied or downloaded as part of the Materials and is not removed or obscured, and provided you do not edit, modify, alter or enhance the Materials. Please refer to our Website User Agreement for more details.

\section{Order now!}

Reprints of this article can also be ordered at http://www.dekker.com/servlet/product/DOI/101081CLT100100953 